\title{
Mapping patterns of well-being and quality of life in extended Europe
}

\author{
Jenny Assi • Mario Lucchini • Amedeo Spagnolo
}

Received: 12 October 2011 / Accepted: 11 January 2012/Published online: 24 January 2012

(C) Springer-Verlag 2012

\begin{abstract}
In this paper, we have applied a powerful clustering procedure (the twostep cluster analysis or BIRCH algorithm) to a set of non-monetary indicators of well-being and quality of life taken from the first four waves of the European Social Survey. By employing this technique, we have identified nine clusters of people characterized by different forms of well-being and quality of life, while preserving as much as possible the multidimensional information contained in the preselected indicators. We then analyzed the distribution of the clusters among the various European countries, finding significant differences among the groups of Nordic countries, Continental European countries, Mediterranean European countries and Eastern European countries in the chances of belonging to the nine forms of wellbeing and quality of life previously identified. On average, citizens of the Nordic countries, but also those of Switzerland and Luxembourg, have a higher chance of belonging to cumulative clusters of well-being than countries in Continental Europe and Eastern Europe. In very concise terms, the former appear to be somewhat protected from the risk of incurring the more severe forms of material deprivation, distrust of others and of institutions, poor health and relational isolation. In contrast, Eastern Europeans are characterized by particularly pronounced levels of deprivation across multiple dimensions.
\end{abstract}

Keywords Well-being - Quality of life · Two-step cluster analysis · European social survey

\footnotetext{
J. Assi $(\bowtie) \cdot$ M. Lucchini

Department of Business and Social Sciences (DSAS), University of Applied Sciences and Arts of Southern Switzerland (SUPSI), Palazzo E, 6928 Manno, Switzerland e-mail: jenny.assi@supsi.ch
}

\section{A. Spagnolo}

Istituto per lo Sviluppo della Formazione Professionale dei Lavoratori (ISFOL),

Corso d'Italia 33, Rome, Italy 


\section{JEL Classification I30}

\section{Introduction}

This paper seeks to contribute to the development of a conceptual and methodological framework for the identification of different forms of well-being and quality of life in contemporary extended Europe. As is widely noted in the literature, most studies of well-being are based on monetary indicators or synthetic indices which capture only the economic dimension, ignoring other equally important dimensions such as health, emotional capital, relational support, trust in others and in institutions, and degree of satisfaction with important aspects of daily life. In recent decades, social researchers have increasingly relied on abstract notionssuch as those of well-being, quality of life, happiness, capabilities and functionings - to represent complex processes that are only partially inferable by the use of individual indicators, or researchers have used synthetic indices which in fact excessively compress the multidimensionality involved in the phenomena in question.

In this work, we intend to supply a complement to the traditional economic measurements by working with subjective, non-monetary indicators of well-being and identifying truly multidimensional measurements. To this purpose, eleven indicators have been selected from the first four waves of the European Social Survey (ESS). These indicators are expressive of trust in people, understanding of political speeches, trust in democratic institutions, trust in institutions delegated to the control of social order, satisfaction with life in general, satisfaction with the national government, satisfaction with the health system, economic-financial wellbeing/deprivation of the family, relational capital, self-assessed health, quality of life and degree of security in the environment. The theoretical framework to which we refer in the selection of indicators is that of subjective well-being and quality of life, which are known to have much in common.

In order to properly represent the multidimensionality of the concept of subjective well-being and quality of life, we have used a particular procedure of clustering (two-step cluster or BIRCH algorithm), which has allowed us to identify nine prototypical forms of well-being and quality of life in contemporary extended Europe. Secondly, we have analyzed the spread of these prototypical forms within the 24 selected countries: Austria, Belgium, Switzerland, The Czech Republic, Germany, Denmark, Estonia, Spain, Finland, France, The United Kingdom, Greece, Hungary, Ireland, Italy, Luxembourg, The Netherlands, Norway, Poland, Portugal, Sweden, Slovenia, Slovakia and Ukraine.

As expected, the distribution of the nine forms of well-being and quality of life which we have identified is largely based on the country of residence. On average, citizens of the Nordic countries, but also those of Switzerland and Luxembourg, have a higher chance of belonging to clusters of cumulative well-being than countries in continental Europe and Eastern Europe. In very concise terms, the former appear to be somewhat protected from the risk of being subject to material deprivation, distrust of others and of institutions, mental and physical illness and 
relational isolation. Conversely, Ukraine, Poland, Portugal, Hungary, The Czech Republic, Slovakia, Greece and Estonia are particularly affected by more severe forms of multidimensional malaise. The remaining countries occupy an intermediate position between these two extremes of multidimensional well-being and deprivation.

\section{Theoretical framework}

For the purpose of measuring well-being, the traditional economic approach has always focused on monetary indicators of an objective type, that is, data that are easy to operationalize, such as income, consumption and assets. Within this theoretical perspective, which excludes unobservable subjective cognitive and emotional states, wealth is regarded as the best proxy for happiness and life satisfaction; broadly speaking, it is expected that higher incomes correspond to the best opportunities in life and therefore to the best chances of enjoying a sense of well-being.

With utilitarianism, there is a shift of economists' attention from objective factors, such as wealth, to subjective factors such as the extent to which preferences are satisfied (cf. Bruni 2002, 2004). The individual is represented in the neoclassical economic approach as a rational actor able to maximize pleasure (or utility) and to minimize unhappiness (or pain). The underlying assumption is the firm conviction that human behavior is always understandable from a consideration of an individual's self-interest. The starting point for the analysis of rationality is overt behavior from which preferences, beliefs and motives of action are inferred.

In recent years, the equation that confirms a function of identity between wellbeing and material resources or between well-being and utility has been questioned by numerous scholars who have observed that income, assets, consumption and utility maximization do not necessarily indicate a connection of complete synonymy with personal, complex emotional experiences variously labeled as happiness, personal fulfilment, feeling good, having a sense of satisfaction, fullness of life and human flourishing (cf. Easterlin 1974; Scitovsky 1976; Fuentes and Rojas 2001; Haller and Hadler 2006; Sen 1980, 1985).

As documented in several studies, objective and subjective well-being are influenced not only by economic elements but also by relational and psychophysical factors which are as important as, or perhaps even more important than, wealth, such as health, social relationships, beliefs, personality traits, purposeful activity(cf. Gasper 2007).

Moreover, there is a significant amount of literature from behavioral economics and psychology which has found that people display bounded rationality; that is, they deviate from the rational economic agent in that they are driven by irrational and inconsistent preferences (Kahneman and Krueger 2006; Simon 1982).

According to Nisbett and Ross (1980), people are not in fact able to choose what will make them truly happy in a totally conscious manner. Decisional utility, given the preferences associated with individual choices, cannot therefore be considered a proxy for substantial utility, that is to say, utility experienced firsthand. 
Following from these criticisms, in more recent years, the issue of well-being has been investigated by numerous researchers from several disciplinary fields (economics, sociology and psychology) and has been variously conceptualized as subjective well-being (commonly abbreviated as SWB) (Kahneman 2007; Diener et al. 1999; Veenhoven 2010; Frey and Stutzer 2002; Bruni 2004; Easterlin 2003; Alesina et al. 2002), capabilities and functionings ${ }^{1}$ (Sen 1980; Nussbaum 2000) and quality of life (QoL) (Cantril 1965; Allardt 1976; Andrews and Withey 1976).

Scholars interested in studying well-being in multidimensional terms are generally grouped together within two categories: those who follow the approach of capabilities and those who adhere to the approach of subjective well-being. The former prefer to conceptualize well-being in eudaemonic terms and generally refer back to the Aristotelian philosophical tradition, linked to the expression of the values of growth and development of the person (human flourishing), while the latter resort to hedonic descriptions centered on the experience of pleasure and positive feelings, following in the footsteps of Benthamite philosophy (cf. Bruni 2002).

As part of the capability approach, the concept of well-being is understood in terms of freedom of choice; it refers to the ability of individuals to achieve freely chosen aims and of access to reasoningly valued functionings (Gasper 2007). Needless to say, capabilities and functionings represent concepts at a high level of semantic abstraction and as such impose a number of critical points when we move from theorization to operationalization (cf. Veenhoven 2010). To better clarify, the quantification of capabilities requires something more than a simple measurement of the subject's satisfaction with reference to a set of indicators of quality of life.

Unlike the capability approach, which focuses on the freedom to endorse valuable beings and doings, the SWB approach focuses on constructs with less semantic abstraction such as hedonic pleasure, emotional responses, people's happiness, domain satisfactions and global judgments of life satisfaction (Diener et al. 1999, Veenhoven 2010). Researchers working within the framework of SWB generally distinguish the hedonic components of well-being, such as moods, emotions and affects, from those cognitive components associated with indicators of satisfaction toward several aspects of current and future life (cf. Diener et al. 1999).

The success of the capabilities and SWB approaches is largely due to the fact that they constitute multidimensional theories of well-being, and as such rely on a complex set of indicators which refer to various aspects of existence, as well as to indicators of economic wealth (Gasper 2007).

Finally, we must mention the rich sociological literature on the topic of quality of life, which is closely connected to the phenomenon of multidimensional well-being. The approach of quality of life has stimulated a deeper reflection on the many concerns related to various aspects of daily life-such as family, home, health, work, leisure, district of residence, school, sanitation, transport-which, in effect, are important components of well-being. This approach brings particular attention

\footnotetext{
${ }^{1}$ In the terminology of Sen (1985), functionings are states and activities which have value for the individual.
} 
to subjective and qualitative aspects of experience, the dimension of love (loving relationships, social networks) and well-being (personal fulfillment and psychophysical well-being), as well as possessions (material conditions of existence), none of which are perfectly inferable from monetary indicators (Campbell et al. 1976; Allardt 1976; Cantril 1965; Bradburn 1969; Andrews and Withey 1976).

Today many scholars call attention to the far from marginal discrepancies that emerge from a comparison of the monetary indicators traditionally used by economists with the non-monetary indicators of subjective well-being and quality of life (Argyle 1987; Diener and Suh 1997; Ekins and Max-Neef 1992; Frey and Stutzer 2002; Kahneman et al. 1999; Pichler 2006; Sen 1985; Veenhoven 2002). They report the impossibility of deriving the social progress achieved by a given country within a given historical context on the basis of the gross domestic product, and totally aside from those properties which constitute the fundamental component of feeling good, such as self-perceived health, degree of relational support, confidence in major institutions expressed by citizens, satisfaction with the health system, the labor market and the educational system, evaluation of the surrounding environment, access to health care, and so on.

In the past 30 years, several studies have focused attention on the relationship between average levels of satisfaction with life and macro-factors such as gross domestic product (Easterlin 1974), the degree of social inequality (Wilkinson and Pickett 2009), cultural factors (Inglehart and Rabier 1986), politics (Inglehart and Klingemann 2000), the level of democracy (Frey and Stutzer 2002) and the degree of generosity of the welfare state (Kumlin and Rothstein 2005; Pacek and Radcliff 2008). Most of these studies are based on variables measured at the macro-level, so there is always the risk of running up against the so-called ecological fallacy, that is, the distortion that can occur when an association detected at a macro-level is transferred to a micro level.

In recent years, various studies have been conducted in different European countries on a set of indicators of quality of life and well-being as subjectively perceived from which a clear order may be outlined ${ }^{2}$ : Denmark and Ukraine are, respectively, located at the top and bottom of the rankings, both with reference to personal well-being (measured in terms of positive and negative emotions, resilience, self-confidence, vitality, etc.) and to social well-being (expressed on the basis of indicators of relational capital, trust in others and other experiences of social participation). Even when the various indicators of personal and social wellbeing are combined within a synthetic index, it is clearly shown that the Scandinavian countries, to which Switzerland is also added, firmly occupy the top places of the order, while the countries of Central and Eastern Europe are permanently at the bottom. By comparing profiles of subjective well-being in various European countries, particularly relevant differences emerge with respect to those detected by using the standard monetary indicators. For example, France and Finland, while showing basically similar levels of GDP per capita and having the

\footnotetext{
${ }^{2}$ For further details see the report of the Second European Quality of Life Survey (2009) and Michaelson et al. (2009).
} 
same score on the index of human development (which combines GDP, life expectancy and education), are positioned at a certain distance from one another both on the scale of personal well-being and on that of social well-being (cf. Michaelson et al. 2009).

From many quarters, and with increasing insistence, there has been a call for a semantic expansion of the concept of economic wealth/deprivation in a larger construct-precisely, that of well-being and quality of life-capable of incorporating multiple aspects of experiences which have scarcely been examined: personality traits, aspirations, processes of psychological adjustment, relational qualities, trust in other people and institutions, quality of life related to the surrounding environment, perceived health, etc. (Frey and Stutzer 2002; Easterlin 1974; Stiglitz et al. 2009).

Recent methodological developments, as well as the availability of extensive databases related to multiple indicators of quality of life, have created a 'rich toolbox' with which to reach a deeper understanding of the phenomenon of wellbeing in truly multidimensional terms. In the last three decades, many social researchers have developed multidimensional measures of well-being in order to overcome the limitations of conventional monetary approaches. Unfortunately, many of these approaches are based on variables measured at a macro-level (for example, the Human Development Index) or on synthetic indices, which are obtained by using data measured at the individual level, but which actually end up sacrificing the multidimensional nature of the phenomena. There are different techniques for obtaining synthetic indicators of quality of life and well-being; the most widespread are those which belong to the family of factor analysis methods (cf. Somarriba and Pena 2009). Finally, other researchers express the concept of subjective well-being by using a single global indicator of happiness which is configured as an ordinal scale. Such a variable is expressed in statistical regression models as a function of a set of predictors which refer to demographic characteristics, psychological traits, life circumstances, contextual factors, etc.

Our intention is rather to develop a truly multidimensional approach by using a powerful cluster procedure capable of producing a taxonomy of highly informative content of the forms of well-being and quality of life in contemporary Europe without having to break down the subjective indicators into synthetic measurements or fall back on a single indicator of happiness.

The originality of this work consists in the fact that, unlike other contributions in the area of subjective well-being which use synthetic indices and regression models, we set ourselves the aim of identifying segments of homogeneous individuals on the basis of a multidimensional complex of characteristics to which we attribute a merely descriptive meaning. The cluster technique which we will propose allows us to treat the various components of SWB collectively, thereby preserving the complexity of the multidimensional construct without compressing it into a synthetic index or a self-report happiness scale. Among the various and most interesting contributions to the literature which adopt clustering logic for the measurement of well-being and multidimensional deprivation, we refer to Lucchini et al. (2007), Ferro-Luzzi et al. (2008) and Pisati et al. (2010). 


\section{Data and variables}

The data we have used come from the ESS, a cross-sectional sample survey funded by the European Commission (with the 5th Framework Programme), from the European Science Foundation and from the academic funds from individual participating countries. The aim is to describe the attitudes, values, beliefs and behaviors of the various European populations. For the purposes of our analysis, we have prepared a file in which are gathered the first four waves $(2002,2004,2006$ and 2008) of the ESS. It should be noted that not all countries are repeated in the four rounds; for example, Italy appears only in the first two waves (2002 and 2004), while Cyprus appears only once (2008). For the objective which we set, eleven indicators were identified among a wide range of available items that put into operation distinct dimensions of the phenomena of well-being and quality of life.

The choice of indicators was made on the basis of the theoretical approach developed by Diener et al. (1999). This approach considers subjective well-being as a "broad category of phenomena that includes people's emotional responses, domain satisfactions and global judgments of life satisfaction." As regards Diener's approach, we focus on indicators which express cognitive evaluations of life satisfaction and domain.

We have decided to eliminate indicators excessively associated with one another for two reasons: firstly, with this strategy, we are able to simplify our models as much as possible, and secondly, selecting one or only a few indicators for each relevant dimension protects us from the risk of producing distorted classifications in which greater emphasis would be given to those dimensions represented by a higher number of indicators. The dimensions involved in the construct of well-being and quality of life to which we have made explicit reference are in order:

- Generalized trust, which we could also define as moralistic trust (Uslaner 2002), attributed to external entities, to institutions and to people one doesn't know (Berggren and Jordahl 2006). By way of clarification, it should be noted that some scholars define trust in other people and institutions as a non-relational component of social capital (Bartolini et al. 2008);

- Understanding of political speeches which is measured by only one indicator and which should represent a proxy of participation or of social centrality;

- Satisfaction with life as measured by a self-anchoring scale of ten positions;

- Satisfaction with the functioning of institutions which is inferred by using two scales of satisfaction: one related to the conduct of the government and the other to the operation of the health system;

- Social capital of bonding, operationalized on the basis of the frequency with which the person interviewed spends free time with friends, relatives or business associates (cf. Woolcock and Sweetser 2002);

- Quality of the surrounding social environment, inferred by taking into account the perception of security/insecurity toward the district of residence;

- Subjective health, as measured with the use of only one indicator of selfperception. This is always a self-anchoring scale of five positions which is widely used in the epidemiological field and appears to be strongly correlated with life expectancy and with many objective parameters of physical health; 
Table 1 Well-being and quality of life indicators

Items

Scale of

measurement

Generalized trust

Do you think that most people would try to take advantage

of you if they got the chance, or would they try to be fair?

Trust in country's parliament

Scale $0-10$

Trust in the police

Scale $0-10$

Understanding of political speeches

How difficult or easy do you find it to make up your mind about political issues?

Dummy $1 / 0$

Satisfaction with life

How satisfied are you with your life as a whole nowadays?

Scale $0-10$

Satisfaction with the functioning of institutions

Thinking about the government, how satisfied are you with

Scale $0-10$ the way it is doing its job?

What do you think overall about the state of health services in your country nowadays?

Scale $0-10$

Social capital of bonding

How often do you meet socially with friends, relatives or work colleagues?

Scale 1-7

Quality of the surrounding social environment

How safe do you-or would you-feel walking alone in your area after dark?

Scale 1-4

Subjective health

How is your health in general?

Scale 1-5

Economic deprivation

How do you feel about your household's income nowadays?

Scale $1-4$

- Economic deprivation, inferred by using a five-position scale which describes satisfaction with the economic/financial situation of the family (Table 1).

As for the data used for the implementation of the cluster analysis, it was decided to select a sub-sample of 2,436 individuals for each of the 24 countries. This device allowed us to avoid forms of well-being and quality of life becoming affected by different sample sizes of the countries that appear in the cumulative file ESS. For the purposes of our analysis, we have considered Austria, Belgium, Switzerland, The Czech Republic, Germany, Denmark, Estonia, Spain, Finland, France, The United Kingdom, Greece, Hungary, Ireland, Italy, Luxembourg, The Netherlands, Norway, Poland, Portugal, Sweden, Slovenia, Slovakia and Ukraine (Table 2). Given that there are some values missing from the indicators chosen, the effective size of the sub-samples on which the analysis was actually performed deviate slightly from the theoretical threshold of 2,436 cases and are reported in Table 3.

\section{Methods}

As mentioned in the section on theory and previous research, not all the approaches used in the literature manage to adequately represent the multidimensional nature of 
Table 2 Theoretical distribution of observations arranged separately for countries and waves

\begin{tabular}{|c|c|c|c|c|c|}
\hline & Wave 1 & Wave 2 & Wave 3 & Wave 4 & Total \\
\hline AT & 801 & 801 & 834 & 0 & 2,436 \\
\hline $\mathrm{BE}$ & 617 & 586 & 611 & 622 & 2,436 \\
\hline $\mathrm{CH}$ & 650 & 674 & 563 & 549 & 2,436 \\
\hline $\mathrm{CZ}$ & 857 & 1,579 & 0 & 0 & 2,436 \\
\hline DE & 635 & 613 & 590 & 598 & 2,436 \\
\hline DK & 610 & 563 & 595 & 668 & 2,436 \\
\hline $\mathrm{EE}$ & 0 & 917 & 680 & 839 & 2,436 \\
\hline ES & 496 & 525 & 618 & 797 & 2,436 \\
\hline FI & 601 & 597 & 567 & 671 & 2,436 \\
\hline FR & 0 & 0 & 1,211 & 1,225 & 2,436 \\
\hline GB & 570 & 518 & 689 & 659 & 2,436 \\
\hline GR & 1,246 & 1,190 & 0 & 0 & 2,436 \\
\hline $\mathrm{HU}$ & 627 & 597 & 593 & 619 & 2,436 \\
\hline IE & 0 & 1,397 & 1,039 & 0 & 2,436 \\
\hline IT & 1,077 & 1,359 & 0 & 0 & 2,436 \\
\hline LU & 1,143 & 1,293 & 0 & 0 & 2,436 \\
\hline NL & 721 & 613 & 568 & 534 & 2,436 \\
\hline NO & 696 & 595 & 613 & 532 & 2,436 \\
\hline PL & 721 & 565 & 583 & 567 & 2,436 \\
\hline PT & 425 & 651 & 660 & 700 & 2,436 \\
\hline SE & 644 & 635 & 554 & 603 & 2,436 \\
\hline SI & 657 & 602 & 620 & 557 & 2,436 \\
\hline SK & 0 & 424 & 998 & 1,014 & 2,436 \\
\hline UA & 0 & 1,145 & 1,291 & 0 & 2,436 \\
\hline Total & 13,794 & 18,439 & 14,477 & 11,754 & 58,464 \\
\hline
\end{tabular}

complex phenomena such as well-being and quality of life. Many studies in this domain are limited to developing composite indices by aggregating a certain number of indicators which represent very different dimensions among themselves, such as health, relational capital, quality of the surrounding environment and economic deprivation. The risk of using these indices is that this leads to a flattening of multidimensionality along a one-dimensional continuum. On the other hand, cluster analysis procedures show a higher investigative power than synthetic indices when the goal is to capture the multidimensional structure of the phenomena through the identification of homogeneous groups of objects based on a complex set of indicators.

Among the various cluster techniques available, we chose to adopt the two-step cluster analysis, also called the BIRCH (Balanced Iterative Reducing and Clustering using Hierarchies) clustering method (Zhang, Ramakrishnan and Livny 1996). This classification algorithm produces a compression of large sets of $\mathrm{N} d$-dimensional vectors or objects $\left\{o_{i}\right\}$ based on the notion of a clustering feature $(\mathrm{CF})$ and a clustering feature tree ( $\mathrm{CF}$ tree), which are used to summarize cluster 
Table 3 Distribution of observations used in the cluster analysis arranged separately for countries and waves

\begin{tabular}{|c|c|c|c|c|c|}
\hline & Wave 1 & Wave 2 & Wave 3 & Wave 4 & Total \\
\hline AT & 793 & 791 & 826 & 0 & 2,410 \\
\hline $\mathrm{BE}$ & 615 & 584 & 611 & 622 & 2,432 \\
\hline $\mathrm{CH}$ & 648 & 672 & 561 & 548 & 2,429 \\
\hline CZ & 840 & 1,560 & 0 & 0 & 2,400 \\
\hline $\mathrm{DE}$ & 634 & 611 & 587 & 598 & 2,430 \\
\hline DK & 609 & 561 & 593 & 668 & 2,431 \\
\hline $\mathrm{EE}$ & 0 & 906 & 672 & 826 & 2,404 \\
\hline ES & 494 & 523 & 615 & 792 & 2,424 \\
\hline FI & 600 & 597 & 564 & 671 & 2,432 \\
\hline FR & 0 & 0 & 1,210 & 1,221 & 2,431 \\
\hline GB & 570 & 512 & 686 & 656 & 2,424 \\
\hline GR & 1,241 & 1,189 & 0 & 0 & 2,430 \\
\hline $\mathrm{HU}$ & 623 & 594 & 585 & 615 & 2,417 \\
\hline IE & 0 & 1,396 & 1,030 & 0 & 2,426 \\
\hline IT & 1,075 & 1,356 & 0 & 0 & 2,431 \\
\hline LU & 1,132 & 1,288 & 0 & 0 & 2,420 \\
\hline NL & 719 & 611 & 567 & 534 & 2,431 \\
\hline NO & 696 & 595 & 613 & 531 & 2,435 \\
\hline PL & 708 & 558 & 573 & 560 & 2,399 \\
\hline PT & 424 & 647 & 654 & 695 & 2,420 \\
\hline SE & 641 & 632 & 554 & 603 & 2,430 \\
\hline SI & 656 & 599 & 619 & 554 & 2,428 \\
\hline SK & 0 & 419 & 988 & 1,005 & 2,412 \\
\hline UA & 0 & 1,126 & 1,277 & 0 & 2,403 \\
\hline Total & 13,718 & 18,327 & 14,385 & 11,699 & 58,129 \\
\hline
\end{tabular}

representations. A CF is a triplet of numbers (N, LS, SS), summarizing information about sub-clusters of data points or multidimensional objects, where $\mathrm{N}$ is the number of points in the cluster, LS is the linear sum of the points and SS is the sum of squares of the points. A clustering feature is a summary of the zero, first and second moments of the sub-cluster. These statistics are sufficient to compute a number of different inter-cluster distance measures. The $\mathrm{CF}_{3}$ entry of the sub-cluster is formed by merging two disjoint sub-clusters $\mathrm{CF}_{1}$ and $\mathrm{CF}_{2}$ as follows: $\mathrm{CF}_{3}=\mathrm{CF}_{1}+\mathrm{CF}_{3}=\left(\mathrm{N}_{1}+\mathrm{N}_{2}, \mathrm{LS}_{1}+\mathrm{LS}_{2}, \mathrm{SS}_{1}+\mathrm{SS}_{2}\right)$.

A CF tree is a height-balanced tree which efficiently stores the clustering features and consists of non-leaf nodes and leaf nodes. Non-leaf nodes represent sub-clusters summarizing clustering information about their children or entries. The size of the $\mathrm{CF}$ tree is influenced by two parameters: the branching factor (B) and the threshold (T). The branching factor specifies the maximum number of children a non-leaf node can have, and the threshold parameter specifies the maximum diameter of the sub-clusters stored at the leaf nodes of the tree. 
Table 4 Distribution of observation among clusters

\begin{tabular}{lcc}
\hline Cluster & Number of cases & Percentage \\
\hline 1 & 6,870 & 11,82 \\
2 & 5,657 & 9,73 \\
3 & 6,653 & 11,45 \\
4 & 5,572 & 9,59 \\
5 & 11,723 & 20,17 \\
6 & 5,883 & 10,12 \\
7 & 6,689 & 11,51 \\
8 & 3,887 & 6,69 \\
9 & 5,195 & 8,94 \\
\hline
\end{tabular}

The BIRCH algorithm consists of two steps: in the first step, the algorithm performs a sequential scan over all data points and dynamically builds a CF tree as the objects are inserted. A point or object is inserted into the closest leaf entry by inserting the corresponding $\mathrm{CF}$ value. An entry in the leaf can absorb the new point if the diameter of the sub-cluster stored after the insertion is not larger than the threshold value. It is possible to modify the threshold in order to change the size of the CF tree. In the second step, after the CF tree is built, a selected clustering algorithm can be run to cluster the leaf nodes of the CF tree.

This technique is capable of handling both continuous and categorical variables and of automatically selecting the optimal number of groups. The assumptions underlying this technique are: the assumption of independence of the variables used, the assumption of normal distribution of continuous variables, and the assumption of polynomial distribution of categorical variables. By way of clarification, we go back to confirm that the indicators selected for the analysis of clusters have been normalized. In short, the Two-Step Cluster Algorithm allows us to allocate cases to a number of sub-clusters in a phase of preclustering in order to reduce the size of the matrix containing the distances between all possible pairs of cases. Subsequently, these sub-clusters are used as input for a hierarchical cluster analysis in order to obtain a desired number of clusters. It is also possible to rely on statistical criteria to evaluate the correct number of clusters. ${ }^{3}$ On the basis of the experimentation and statistical criteria, we opted for a nine-cluster solution, which offers a reasonable balance between detail and parsimony. ${ }^{4}$

\section{Results}

Table 4 shows the distribution of observations among the nine groups which we identified with the Two-Step Cluster Analysis procedure. Each group contains an

\footnotetext{
${ }^{3}$ The most often used criteria are the Bayesian Information Criterion (BIC) and the Akaike Information Criterion (AIC).

${ }^{4}$ The initial threshold for changing the distance was set to zero. The maximum ramifications for leaf node have been fixed at 8 value. Finally, the structure has a maximum depth of three levels and the maximum number of possible nodes was set at 585. For the purposes of our analysis we used the TwoStep Clustering procedure implemented in SPSS (Zhang et al. 1996).
} 
adequate proportion of cases, that is, neither particularly narrow nor particularly wide. Cluster 5 is the one with the largest number of observations (about 20\%), while Cluster 8 is the smallest, with about $7 \%$ of cases.

In Table 5, we report the averages of the indicators within each cluster and the respective sample mean from which deviation it is possible to infer the semantics expressed by each of the nine prototypical forms of well-being and quality of life which we have identified.

In Table 6, we offer a synthetic description of nine clusters. More specifically, we have developed an analytical strategy by which to transform the deviations of the components as regards the sample mean in alphanumeric codes represented by positive $(+)$ and negative $(-)$ signs. The number of + or - signs is proportional to the deviation. This procedure takes into account any possible asymmetric distribution of the chosen indicators. Here is the algorithm for the transformation of deviations of the components into a string of positive $(+)$ and negative $(-)$ signs:

For each indicator $X_{j}(j=1, \ldots, 11)$, we have calculated the respective sampling variance $V\left(X_{j}\right)^{5}$;

1. For each indicator $X_{j}$, we have calculated three threshold values, as follows:

$$
\begin{aligned}
& t_{1 j}=\left|\ln \left(\frac{p_{j}+V\left(X_{j}\right) \times 0.75}{p_{j}}\right)\right| \\
& t_{2 j}=\left|\ln \left(\frac{p_{j}+V\left(X_{j}\right) \times 1.5}{p_{j}}\right)\right| \\
& t_{3 j}=\left|\ln \left(\frac{p_{j}+V\left(X_{j}\right) \times 2.25}{p_{j}}\right)\right| .
\end{aligned}
$$

2. For each indicator $X_{j}$, we have calculated the average within each cluster $C g(g=1, \ldots, 9): p_{j \mid g}=\operatorname{Pr}\left(X_{j}=1 \mid C_{g}\right)$.

3. For each indicator $X_{j}$ and each cluster $C_{g}$, we have calculated the deviation of the specific average of clusters compared to the sample average (overall mean): $\delta_{j g}=\ln \left(p_{j \mid g} / p_{j}\right)$.

4. We have transformed the values of the deviations $\delta_{j g}$ into a corresponding set $s_{j g}$ according to the following rules:

$$
s_{j g}=\left\{\begin{array}{ll}
3 & \text { if } \delta_{j g} \geq t_{3 j} \\
2 & \text { if } t_{2 j} \leq \delta_{j g}<t_{3 j} \\
1 & \text { if } t_{1 j} \leq \delta_{j g}<t_{2 j} \\
0 & \text { if }-t_{1 j} \leq \delta_{j g}<t_{1 j} \\
-1 & \text { if }-t_{2 j} \leq \delta_{j g}<-t_{1 j} \\
-2 & \text { if }-t_{3 j} \leq \delta_{j g}<-t_{2 j} \\
-3 & \text { if } \delta_{j g}<-t_{3 j}
\end{array} .\right.
$$

\footnotetext{
5 The indicators which are presented as scales (health satisfaction, satisfaction with finances and difficulty in making ends meet) have been normalized.
} 





Table 6 Description of the nine clusters using an alphanumeric code

\begin{tabular}{|c|c|c|c|c|c|c|c|c|c|}
\hline Items & $\mathrm{c} 1$ & $\mathrm{c} 2$ & $\mathrm{c} 3$ & $\mathrm{c} 4$ & $\mathrm{c} 5$ & c6 & c7 & $\mathrm{c} 8$ & c9 \\
\hline $\begin{array}{l}\text { Most people try to take } \\
\text { advantage of you or try to } \\
\text { be fair }\end{array}$ & & & & & +++ & -- & --- & --- & + \\
\hline $\begin{array}{l}\text { Understanding political } \\
\text { speeches }\end{array}$ & + & & - & & ++ & +++ & - & - & --- \\
\hline $\begin{array}{l}\text { Trust in country's } \\
\text { parliament }\end{array}$ & + & + & ++ & ++ & +++ & --- & --- & --- & --- \\
\hline Trust in the police & & + & ++ & ++ & +++ & --- & --- & --- & -- \\
\hline $\begin{array}{l}\text { How satisfied with life as a } \\
\text { whole? }\end{array}$ & + & & & + & +++ & + & --- & --- & \\
\hline $\begin{array}{l}\text { How satisfied with the } \\
\text { national government? }\end{array}$ & & + & ++ & ++ & +++ & --- & --- & --- & --- \\
\hline $\begin{array}{l}\text { State of health services in } \\
\text { country nowadays }\end{array}$ & & & ++ & + & +++ & -- & --- & --- & --- \\
\hline Household's income & +++ & & -- & & +++ & ++ & --- & --- & \\
\hline $\begin{array}{l}\text { How often meet socially } \\
\text { with friends, relatives or } \\
\text { colleagues? }\end{array}$ & + & --- & + & + & + & + & ++ & --- & \\
\hline $\begin{array}{l}\text { Feeling of safety while } \\
\text { walking alone in local area } \\
\text { after dark }\end{array}$ & ++ & & +++ & --- & +++ & + & -- & --- & \\
\hline Subjective general health & -- & -- & + & & +++ & +++ & --- & --- & \\
\hline
\end{tabular}

In conclusion, we have reported the values $s_{j g}$ transformed into a sequence of symbols $(+/-)$, as appears in Table 6 . The codes marked by a series of + and indicate the intensity with which the expected value of a given item within a given cluster moves away from the respective sample mean. Let us now give a substantive meaning to the clusters identified.

Group 1: Economically well off, but in poor health. The first cluster groups together $11.8 \%$ of the sample and is composed of individuals who are, on average, in poor health, but show a high material well-being, a feeling of relative safety in the surrounding environment and an adequate understanding of political speeches. The averages relative to the indicators of confidence in parliament, satisfaction with life and social relations appear to be slightly above the overall average.

Group 2: Isolated and in poor health. The second group, which amounts to $9.7 \%$ of the observations, consists of those who are quite confident in parliament and law enforcement and are also quite satisfied with the functioning of the national government. The members of this segment are, on average, in poor health and have very little opportunity to meet friends, relatives and colleagues. Unlike the previous cluster, in this group we find individuals who tend to be isolated and whose economic resources follow the sample mean.

Group 3: Economically deprived but secure and confident in institutions. The third group makes up $11.4 \%$ of the sample size and consists of persons deprived in 
economic terms, expressing satisfaction with the functioning of the government and the national health system, together with a high degree of trust in institutions and law enforcement. The opportunities for meeting with friends, relatives and colleagues are higher than average. In addition, the subjects belonging to this group show some difficulty in understanding politics. These individuals enjoy good health and nurture a strong sense of security within the surrounding area. The level of satisfaction with life comes up to the value of the sample mean.

Group 4: Insecure but confident in institutions. The fourth group brings together $9.6 \%$ of subjects sampled and, ultimately, is a variation on cluster 3 . It is distinguished by a higher degree of satisfaction with life and prosperity. Another fact worthy of consideration is the strong feeling of insecurity within the surrounding area. The level of health and satisfaction with the economic and financial situation roughly follows the average profile of the sample.

Group 5: Well-being in all dimensions. This cluster includes $20.2 \%$ of the sample and consists of individuals with a high degree of satisfaction with life and prosperity. They say they enjoy excellent health, have no difficulty understanding the politics and therefore occupy a position of full social centrality. In addition, they show a high level of trust in others and in institutions, and a high degree of appreciation of the functioning of government and the national health system.

Group 6: Distrustful but in good health and with a high understanding of political discourse. This cluster amounts to $10.1 \%$ of the observations and is composed of individuals with low trust in other people and institutions. Dissatisfaction with the work of the government and the health system is also particularly pronounced. The concentration of individuals who report understanding political discourse and enjoying excellent health is high. This cluster is populated by quite satisfied people who have a good amount of economic and relational capital. Even the perception of security within the surrounding area is above average.

Group 7: Cumulative malaise but with a good amount of relational capital. This cluster brings together $11.5 \%$ of the subjects in the sample. It is characterized by low trust in others and institutions, and a strong dissatisfaction with the work of the government and the health system. Other distinctive features include poor health, a strong feeling of dissatisfaction with life, severe economic deprivation and a feeling of insecurity within the surrounding area. The only component of well-being present is represented by the relatively high frequency of encounters with friends, relatives and colleagues.

Group 8: Cumulative deprivation. The cluster incorporates only $6.6 \%$ of the subjects and represents a variation, in the pejorative sense, on cluster 7 . It is constructed of subjects dissatisfied with life who are in poor economic and health conditions, are very distrustful of others and of institutions, complain about the poor functioning of the government and the health system, and have difficulty understanding politics. Compared to the previous group, members of cluster 8 appear to be deprived of any relational capital and therefore, in effect, live in particularly disadvantaged conditions. 
Group 9: Low understanding of political discourse, distrust and dissatisfaction with institutions. This group accounts for $8.9 \%$ of the sample. Here, we find individuals who show some confidence in other people but not in the parliament or the police. The members of this group are particularly dissatisfied with regard to the functioning of the government and the health system of their country. Another distinctive feature is a great difficulty in understanding politics. With regard to other indicators, there are no notable deviations from the average profile.

To facilitate interpretation of the analysis, we have decided to project the nine clusters onto a two-dimensional space by using a multidimensional scaling procedure (Torgerson 1952) in order to maximize the correlation between the allocation of groups in the data space and the allocation of groups onto the twodimensional plane. Figure 1 reports the results of this projection. The size of each cluster is proportional to its prevalence, that is, the number of cases which are concentrated within it, while the Euclidean distance between clusters reproduces the distance in the data space in terms of well-being and quality of life. As can be seen in Fig. 1, the cluster of cumulative well-being (cluster 5) is maximally far from cluster 8 in the area of multiple deprivation. Similarly, cluster 2 is especially far from cluster 6 whose members are in excellent health and distrust institutions.

From the intersection of forms of SWB and quality of life with the countries of residence, it is clear how the Nordic countries (Denmark, Norway, Finland and Sweden), together with Switzerland and Luxembourg, are characterized by the highest probability of belonging to segment 5 of multidimensional well-being (see Table 7 and Fig. 2). Particularly in Denmark, this probability reaches 61\%. Still looking at the group of Scandinavian countries, the percentage of subjects in conditions of multiple deprivation (belonging to clusters 7 and 8) seems somewhat narrow. Even the probability of belonging to clusters 2, 6 or 9, which, as we have seen, connote forms of social isolation and feelings of distrust of institutions, appear to be relatively small in these countries. The second group of countries which

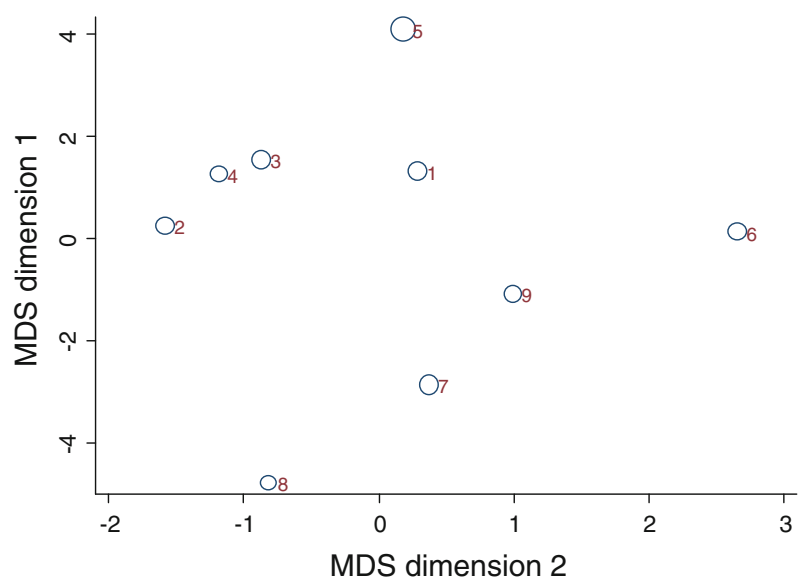

Fig. 1 Projection of the nine clusters in Euclidean space 
Table 7 Probability of cluster's membership conditioned to country of residence

\begin{tabular}{lrrrrrrrrr}
\hline Country & $\mathrm{c} 1$ & \multicolumn{1}{c}{$\mathrm{c} 2$} & \multicolumn{1}{c}{$\mathrm{c3}$} & \multicolumn{1}{c}{$\mathrm{c} 4$} & \multicolumn{1}{c}{$\mathrm{c5}$} & \multicolumn{1}{c}{6} & $\mathrm{c} 7$ & $\mathrm{c} 8$ & $\mathrm{c} 9$ \\
\hline Austria & 12.5 & 8.5 & 13.0 & 8.1 & 27.5 & 14.9 & 6.6 & 1.6 & 7.3 \\
Belgium & 14.2 & 7.7 & 17.6 & 11.5 & 25.2 & 8.6 & 6.9 & 2.1 & 6.3 \\
Switzerland & 12.3 & 5.4 & 14.5 & 11.6 & 43.2 & 6.7 & 2.6 & .5 & 3.3 \\
Czech Republic & 7.9 & 12.9 & 8.8 & 7.1 & 3.8 & 11.2 & 20.0 & 13.2 & 15.0 \\
Germany & 16.3 & 10.5 & 9.9 & 9.1 & 13.5 & 11.8 & 9.4 & 5.7 & 14.0 \\
Denmark & 11.1 & 3.7 & 8.0 & 8.7 & 61.0 & 3.4 & 1.0 & .3 & 2.9 \\
Estonia & 10.2 & 15.1 & 10.2 & 12.6 & 7.2 & 7.0 & 15.5 & 11.2 & 11.0 \\
Spain & 18.2 & 8.0 & 16.1 & 13.3 & 15.2 & 10.4 & 8.3 & 2.2 & 8.4 \\
Finland & 7.9 & 7.7 & 25.2 & 7.2 & 43.3 & 1.9 & 2.4 & .5 & 4.0 \\
France & 16.9 & 6.0 & 12.1 & 12.1 & 15.5 & 14.5 & 11.9 & 3.3 & 7.8 \\
United Kingdom & 10.4 & 8.8 & 11.1 & 16.4 & 15.9 & 12.0 & 9.0 & 3.9 & 12.7 \\
Greece & 2.2 & 22.4 & 18.2 & 7.3 & 6.0 & 11.4 & 13.1 & 12.6 & 7.0 \\
Hungary & 4.9 & 18.7 & 6.5 & 4.1 & 2.4 & 10.4 & 16.2 & 25.1 & 11.7 \\
Ireland & 10.5 & 12.6 & 7.2 & 15.1 & 22.6 & 15.6 & 4.6 & 2.1 & 9.7 \\
Italy & 15.4 & 11.4 & 13.2 & 12.3 & 10.0 & 10.7 & 11.7 & 5.2 & 10.1 \\
Luxembourg & 13.9 & 12.9 & 10.7 & 15.2 & 34.5 & 6.2 & 3.0 & 1.2 & 2.4 \\
The Netherlands & 20.8 & 4.8 & 12.0 & 12.0 & 28.1 & 7.7 & 5.7 & 1.5 & 7.4 \\
Norway & 16.8 & 3.5 & 10.7 & 6.7 & 44.5 & 7.5 & 2.7 & .6 & 7.1 \\
Poland & 6.5 & 12.0 & 6.2 & 4.4 & 1.7 & 16.3 & 16.3 & 13.7 & 23.0 \\
Portugal & 13.2 & 4.7 & 10.8 & 6.2 & 2.1 & 12.2 & 33.0 & 6.5 & 11.4 \\
Sweden & 14.0 & 4.6 & 8.9 & 10.5 & 41.7 & 8.6 & 3.1 & 1.0 & 7.6 \\
Slovenia & 17.1 & 15.1 & 8.5 & 3.2 & 13.0 & 16.6 & 9.6 & 6.2 & 10.9 \\
Slovakia & 8.5 & 11.2 & 11.0 & 10.4 & 4.6 & 13.6 & 23.1 & 9.3 & 8.3 \\
Ukraine & 1.9 & 5.8 & 4.2 & 5.0 & .7 & 3.8 & 41.3 & 31.7 & 5.6 \\
Total & 11.8 & 9.7 & 11.5 & 9.6 & 20.2 & 10.1 & 11.5 & 6.7 & 8.9 \\
\hline & & & & & & & & & \\
& & & & & & & & &
\end{tabular}

clearly takes shape brings together the countries of Continental Europe and the Mediterranean (Spain, France, Germany, Italy, Great Britain, Slovenia, Austria, Belgium, Holland and Ireland). In these countries, the chances of belonging to clusters which express various forms of deprivation and vulnerability $(1,4,6,7,8$, 9) are relatively higher than in the group of Nordic countries. In contrast, the chances of belonging to the multidimensional well-being segment are significantly reduced.

In conclusion, in Ukraine, Poland, Portugal, Hungary, Czech Republic, Slovakia, Greece and Estonia, the percentage of persons belonging to the cluster of multidimensional well-being is particularly low, amounting to a value of between $.7 \%$ in Ukraine and $7.2 \%$ in Estonia. In this group of countries, the probabilities of experiencing cumulative forms of malaise (clusters 7 and 8) as well as various forms of multidimensional vulnerability (clusters 2 and 9) are particularly high. To be more precise, in Hungary and Portugal, approximately $40 \%$ of the subjects belong to clusters of cumulative distress (7 and 8), while in the Czech Republic and Slovakia 


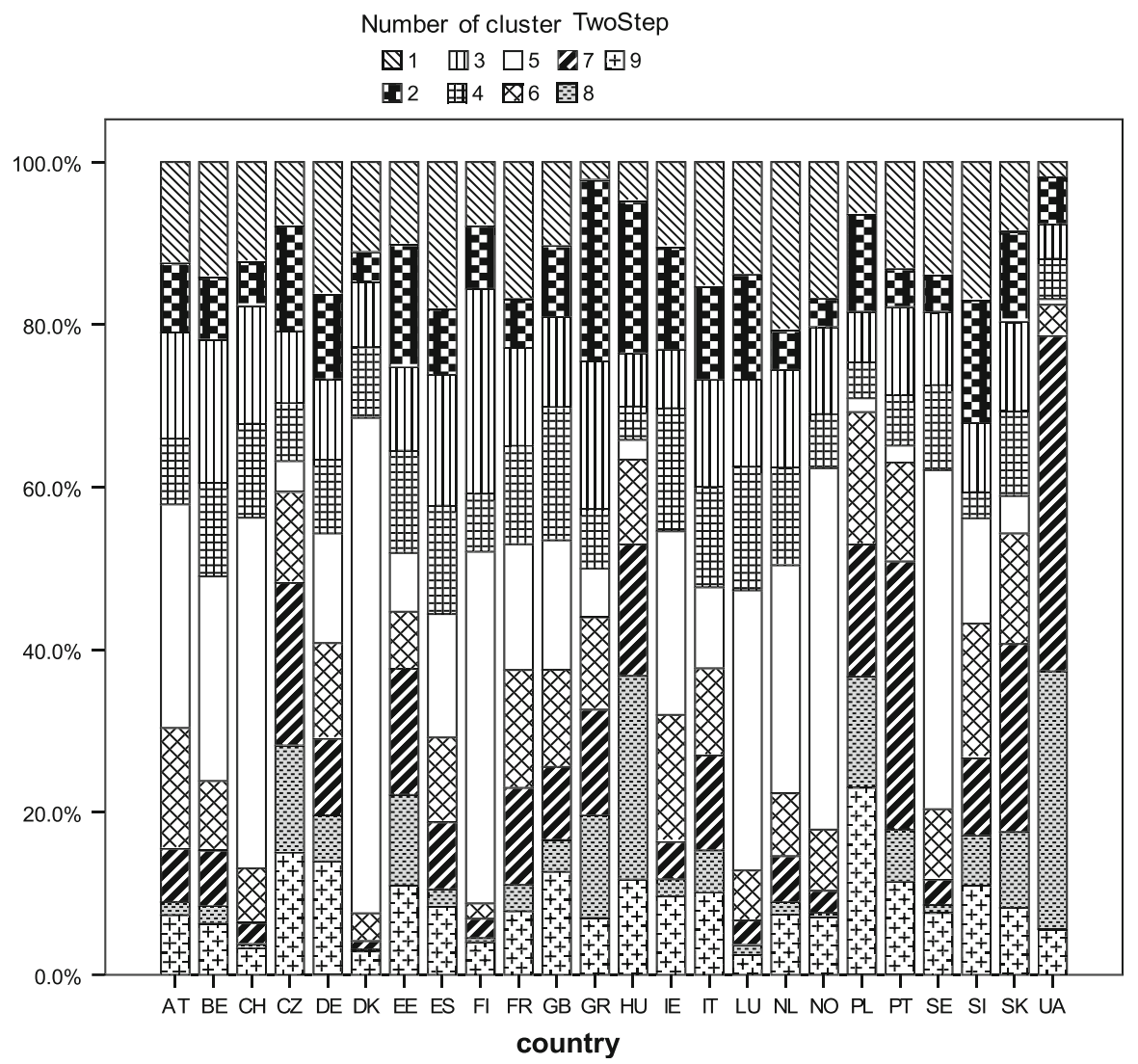

Fig. 2 Probability of cluster's membership conditioned to country of residence

$33 \%$ are found in these categories. The risk of falling into this form of multidimensional deprivation is well above average in Poland (30\%), Estonia $(27 \%)$ and Greece $(26 \%)$.

Finally, Ukraine is a special case since it differs greatly from the Nordic and continental countries but also to some extent from the former communist bloc countries. The probability of people belonging to cluster 7 and 8 is quite high, reaching $73 \%$.

A more analytical reading of Table 7 also indicates that the UK, Ireland and Luxembourg show a relatively higher probability of belonging to cluster 4, which brings together people who harbor a feeling of insecurity toward the surrounding area. In Greece and Hungary, the probability of belonging to cluster 2, which is composed of individuals in poor health and socially isolated, seems particularly higher. Membership in cluster 3, which expresses a form of economic deprivation in combination with a feeling of trust in and satisfaction with the government and major institutions, is relatively more widespread in Finland, Belgium and Greece. Finally, membership in cluster 6, which includes subjects mistrustful of others and 
of institutions but in excellent health and with a high understanding of political discourse, is more widespread in Austria, France, Ireland, Poland and Slovenia.

Finally, we have proposed a hierarchical cluster analysis of countries from the percentage distribution of the forms of well-being and quality of life found in each. The matrix from which the grouping was carried out is made up of 24 cases, representing the selected EU countries, and nine variables, indicating the nine prototypical forms of well-being and quality of life which we have previously identified. To better clarify, each country is described by a vector of nine elements, each of which expresses the probability of belonging to a given cluster. The distance between the points which describe the coordinates of each pair of countries is calculated using Euclidean distance. As a criterion for grouping, we have chosen the procedure known as average linkage, which has allowed us to identify roughly four major groupings of countries (see Fig. 3): the first group of countries with high multi-dimensional well-being-which includes Switzerland, Denmark, Finland, Luxembourg, Norway and Sweden-has a distance equal to or less than 5. A second group of countries with medium levels of multidimensional well-being brings together Austria, Belgium, Germany, Spain, France, The United Kingdom, Ireland, Italy, The Netherlands and Slovenia. To be more precise, this grouping is composed of two sub-groupings of countries which are less than 2 in distance from one another: the first consists of Austria, Belgium, The Netherlands and Ireland, and the second of Spain, France, Germany, Italy, Great Britain and Slovenia. The third group of countries, characterized by malaise in several dimensions, includes The Czech Republic, Estonia, Greece, Hungary, Poland, Portugal and Slovakia, and reveals a distance between the countries of below the value 7 . Finally, the last cluster is represented by a single country-Ukraine-which is characterized by severe multidimensional deprivation. The second and third groups merge around a distance of value 7. In turn, groups 2 and 3 unify at group 1 at a value of 15 . Finally, Ukraine joins the previous groupings at a distance equal to 25 .

\section{Discussion}

Today, social scholars, policy makers and international organizations like the European Commission, the Organisation for Economic Cooperation and Development (OECD), the United Nations (UN) and the World Bank are focused on the need to adopt new instruments for measuring social well-being which go beyond conventional economic measures such as gross domestic product.

To this end, indicators of subjective well-being play a crucial role as they allow us to measure a great variety of aspects related to quality of life from the direct experience of individuals (cf. Diener and Suh 1997). The measures based on subjective indicators form a useful complement to monetary measures based on objective indicators. Of course, there is no perfect overlap between subjective indicators and monetary measures.

In this regard, it should be noted that many studies using non-monetary indicators are limited to building synthetic indices in which multidimensional content is collapsed into the original data. Alternatively, we have proposed a powerful 


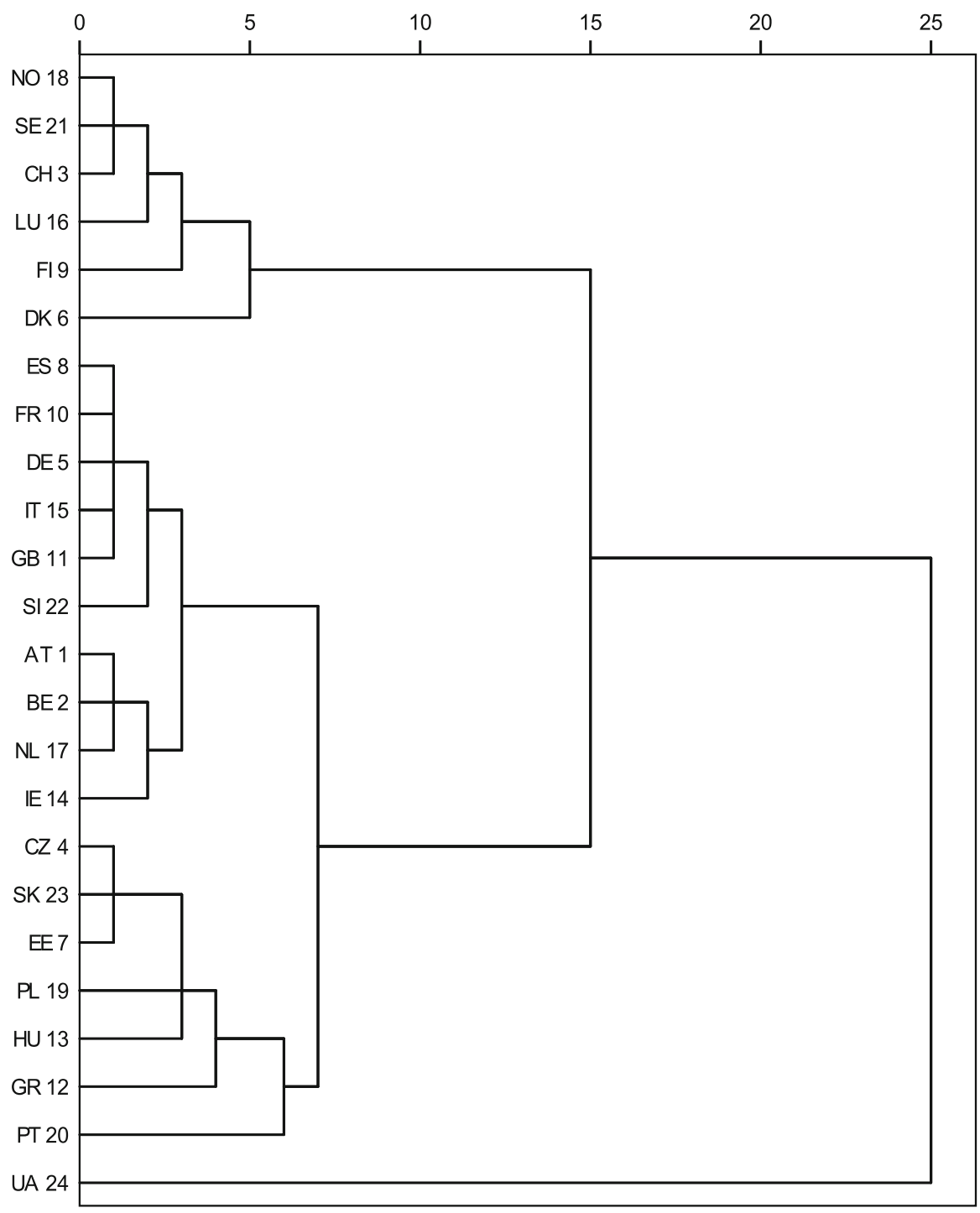

Fig. 3 Hierarchical cluster analysis of countries

clustering procedure-the algorithm $\mathrm{BIRCH}-$ to compress a multidimensional space of indicators of well-being and quality of life while preserving the information contained in the input data as much as possible.

Looking at the distribution of forms of welfare and quality of life in various European countries, it is possible to roughly identify four main country groupings: the first group of countries-Denmark, Finland, Norway and Sweden and also including Switzerland and Luxembourg - has average values on almost all of the selected indicators which are much higher than the sample mean, thereby defining 
this group as a cluster of multidimensional well-being. The second identified group consists of countries which are highly heterogeneous in their socio-institutional structure and level of economic development and which have a medium or medium-high level of multidimensional well-being. This group consists of Austria, Belgium, Cyprus, Germany, Spain, France, The United Kingdom, Ireland, Israel, Italy, The Netherlands and Slovenia. The third group includes both Southern European countries, namely Portugal and Greece, and Eastern European countries, such as The Czech Republic, Estonia, Hungary, Poland and Slovakia. This group is characterized by particularly pronounced levels of deprivation across multiple dimensions. Finally, the last cluster is represented by a single country-Ukraineand is characterized by severe deprivation in almost all indicators. In this group, the average values of most of the indicators examined are systematically lower than in the previous group which, as just argued, is in conditions of relative multidimensional deprivation.

In conclusion, we firmly believe that these clustering procedures applied to nonmonetary indicators constitute a useful supplementary tool to traditional monetary measurements, since they can produce a more comprehensive and organic picture of the plurality of people's life conditions and of their effective means of accessing the economic, social and relational resources which allow them to make autonomous choices regarding their individual existence models.

\section{References}

Alesina A, Di Tella R, McCulloch R (2002) Inequality and happiness: are Europeans and Americans different?. Mimeo, Harvard

Allardt E (1976) Dimensions of welfare in a comparative Scandinavian study. Acta Sociol 19(3):227-239 Andrews FM, Withey SB (1976) Social indicators of well-being. Americans perceptions of life quality. Plenum Press, New York

Argyle M (1987) The psychology of happiness. Methuen, London

Bartolini S, Bilancini E, Pugno M (2008) Did the decline in social capital depress Americans' happiness?. Quaderni del Dipartimento di Economia Politica, Siena University, Siena, p 540

Berggren N, Jordahl H (2006) Free to trust: economic freedom and social capital. Kyklos 59(2):141-169 Bradburn NM (1969) The structure of psychological well-being. Aldine Publishing, Chicago

Bruni L (2002) Felicità e scienza economica-Storia, problemi aperti e spunti teorici. Working papers 48, Department of Economics, University of Milano-Bicocca

Bruni L (2004) The technology of happiness and the tradition of economic science. J Hist Econ Thought 26(01):19-44

Campbell A, Converse PE, Rodgers WL (1976) The quality of American life. Perceptions, evaluations, and satisfactions. Russell Sage Foundation, New York

Cantril H (1965) The pattern of human concerns. Rutgers University Press, New Brunswick

Diener E, Suh EM (1997) Measuring quality of life: economic, social and subjective indicators. Soc Indic Res 40(1-2):189-216

Diener E, Suh EM, Lucas RE, Smith HE (1999) Subjective well-being: three decades of progress. Psychol Bull 125:276-302

Easterlin RA (1974) Does economic growth improve the human lot? In: Paul AD, Melvin WR (eds) Nations and households in economic growth: essays in honor of Moses Abramovitz. Academic Press Inc, New York

Easterlin RA (2003) Explaining happiness. PNAS 100(19):11176-11183

Ekins P, Max-Neef M (1992) Real life economics. Routledge, London 
Ferro-Luzzi G, Flückiger Y, Weber S (2008) A cluster analysis of multidimensional poverty in Switzerland. In: Kakwani N, Silber J (eds) Quantitative approaches to multidimensional poverty measurement. Palgrave MacMillan, London, pp 63-79

Frey B, Stutzer A (2002) Happiness in economics. Princeton University Press, Princeton

Fuentes N, Rojas M (2001) Economic theory and subjective well-being: Mexico. Soc Indic Res 53(3):289-314

Gasper D (2007) What is the capability approach? Its core, rationale, partners and dangers. J Socioecon 36(3):335-359

Haller M, Hadler M (2006) How social relations and structures can produce happiness and unhappiness: an international comparative analysis. Soc Indic Res 75:169-216

Inglehart R, Klingemann HD (2000) Genes, culture, democracy and happiness. In: Diener E, Suh E (eds) Culture and subjective well-being. MIT Press, Cambridge, pp 165-183

Inglehart R, Rabier JR (1986) Aspirations adapt to situations-but why are the Belgians much happier than the French? In: Andrews FM (eds) Research on the quality of life. ISR, Michigan

Kahneman D (2007) Economia della felicità. Il Sole 24 Ore, Milano

Kahneman D, Krueger AB (2006) Developments in the measurement of subjective well-being. J Econ Perspect 20:3-24

Kahneman D, Diener E, Schwarz N (1999) Well-being: the foundations of hedonic psychology. Russell Sage Foundation, New York

Kumlin S, Rothstein B (2005) Making and breaking social capital: the impact of welfare-state institutions. Comp Polit Stud 38:339-365

Lucchini M, Pisati M, Schizzerotto A (2007) Stati di deprivazione e di benessere nell'Italia contemporanea: Un'analisi multidimensionale. In: Brandolini A, Saraceno C (eds) Povertà e benessere: Una geografia delle disuguaglianze in Italia. Il Mulino, Bologna, pp 271-303

Michaelson J, Abdallah S, Steuer N, Thompson S, Marks N (2009) The national accounts of well-being. New Economics Foundation, London

Nisbett RE, Ross L (1980) Human inference: strategies and shortcomings of social judgment. Englewood Cliffs, Pretice-Hall

Nussbaum M (2000) Women and human development: the capabilities approach. Cambridge University Press, Cambridge

Pacek A, Radcliff B (2008) Assessing the welfare state: the politics of happiness. Perspect Polit 6: 267-277

Pichler F (2006) Subjective quality of life of young Europeans: feeling happy but who knows why? Soc Indic Res 75(3):419-444

Pisati M, Whelan C, Lucchini M, Maitre B (2010) Mapping patterns of multiple deprivation using selforganising maps: an application to EU-SILC data for Ireland. Soc Sci Res 39:405-418

Scitovsky T (1976) The joyless economy: an inquiry into human satisfaction and consumer dissatisfaction. Oxford University Press, New York

Sen AK (1980) Equality of what? In: Sterling MM (ed) The tanner lectures on human value. University of Utah Press, Salt Lake City, pp 195-220

Sen AK (1985) Commodities and capabilities. North Holland, Amsterdam

Simon HA (1982) Models of bounded rationality, vol 2. MIT Press, Cambridge

Somarriba N, Pena B (2009) Synthetic indicators of quality of life in Europe. Soc Indic Res 96:115-133

Stiglitz JE, Sen A, Fitoussi JP (2009) Report by the commission on the measurement of economic performance and social progress. The commission: Paris http://www.stiglitz-sen-fitoussi.fr/en/index.htm

Torgerson WS (1952) Multidimensional scaling: theory and method. Psychometrika 17:401-419

Uslaner EM (2002) The moral foundations of trust. Cambridge University Press, New York

Veenhoven R (2002) Why social policy needs subjective indicators. Soc Indic Res 58(1-3):33-46

Veenhoven R (2010) Capability and happiness: conceptual difference and reality links. J Socio-Econ 39(3):344-350

Wilkinson R, Pickett K (2009) The spirit level, why equality is better for everyone. Penguin Books, London

Woolcock M, Sweetser AT (2002) Bright ideas: social capital-the bonds that connect. ADB Rev 34(2):1-26

Zhang T, Ramakrishnan R, Livny M (1996) BIRCH: an efficient data clustering method for very large databases. Technical report, Computer Sciences Department, University of Winsconsin-Madison 